\begin{tabular}{|c|c|c|}
\hline 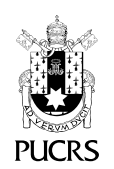 & $\begin{array}{l}\text { ESCOLA DE CIÊNCIAS } \\
\text { DA SAÜDE E DA VIDA }\end{array}$ & $\begin{array}{l}\text { Psico, Porto Alegre, v. 52, n. 1, p. 1-15, jan.-mar. } 2021 \\
\text { e-ISSN: 1980-8623 | ISSN-L: 0103-5371 }\end{array}$ \\
\hline d http:// & doi.org/10.15448/1980-8623.2021.1.36028 & \\
\hline
\end{tabular}

SEÇÃO: ARTIGO

\title{
Significados atribuídos por pais enlutados às suas experiências e aos cuidados da equipe de saúde
}

\author{
Meanings attributed by bereaved parents to their experiences and to the care of the \\ healthcare team
}

Significados atribuidos por los padres en duelo a sus experiencias y a los cuidados del equipo de salud

\section{Cristine Gabrielle da Costa dos Reis ${ }^{1}$}

orcid.org/0000-0002-8935-4715 cristinecostareis@hotmail.com

\section{Alberto Manuel \\ Quintana $^{2}$ \\ orcid.org/0000-0001-7356-6142 albertom.quintana@gmail.com}

Luísa da Rosa Olesiak orcid.org/0000-0002-2635-2675 luisa_drolesiak@hotmail.com

Fernanda Nardino ${ }^{2}$

orcid.org/0000-0002-8453-3941 fernanda.nardino@hotmail.com

\section{Mikaela Aline Bade}

München²

orcid.org/0000-0001-7610-0030 mikaelaaline@hotmail.com

Recebido em: 17 out. 2019 Aprovado em: 18 set. 2020. Publicado em: 17 jun. 2021

\section{(c) (i)}

Artigo está licenciado sob forma de uma licenç Creative Commons Atribuicão 4.0 Internacional.
Resumo: O adoecimento e a morte de uma criança repercutem diretamente na vida dos pais. Diante disso, este artigo, de abordagem qualitativa, objetivou compreender os significados atribuidos por pais enlutados às suas experiências diante da perda do filho e aos cuidados desempenhados pela equipe de saúde. Realizaram-se 11 entrevistas semiestruturadas com pais que perderam filhos crianças em virtude de doença, cujos dados foram tratados conforme análise de conteúdo temática. Os resultados mostraram: a importância da participação no cuidado da criança adoecida e do contato com o filho morto; e as percepções ambivalentes em relação à equipe de saúde, que evidenciaram atenção e comunicação compreensiva e despreparo para a atuação, comunicação inadequada e falta de seguimento na assistência. Destaca-se a importância da comunicação clara e do reconhecimento da perda, além de capacitações aos profissionais para atuarem com situações de morte e luto.

Palavras-chave: morte, luto, relações pais-criança, profissional da saúde

Abstract: The illness and death of a child reverberate directly on parents' lives. Therefore, this qualitative approach paper aimed to comprehend the meanings attributed by bereaved parents to their experiences in front of the loss of their child and to the care performed by the healthcare team. There were conducted 11 semi-structured interviews with parents who had lost their children because of an illness. Data were analyzed according to thematic content analysis. The results demonstrated: the importance of participating on the care of the sick child and the contact with the dead child; ambivalent perceptions towards the healthcare team, which evidences attention and comprehensive communication and shows unpreparedness for the performance, inadequate communication and lack of follow-up on care. It is emphasized the importance of an honest communication and the recognition of the loss, as well as training professionals to work with situations of death and grief

Keywords: death and dying, grief, parent child relations, health professional

Resumen: La enfermedad y la muerte de un niño repercuten directamente en la vida de los padres. Asi, este artículo, de abordaje cualitativa, objetivó comprender los significados atribuidos por los padres en duelo a sus experiencias ante la pérdida de su hijo y a los cuidados desempeñados por el equipo de salud. Se realizaron 11 entrevistas semiestructuradas con padres que perdieron su niño en virtud de una enfermedad, cuyos datos fueron tratados conforme análisis de contenido temático. Los resultados mostraron: la importancia de la participación en el cuidado del niño enfermo y del contacto con el niño muerto; percepciones ambivalentes frente al equipo de salud, evidenciaron atención y comunicación comprensiva y despreparo para la actuación, comunicación inadecuada y falta 
de asistencia continuada. Se destaca la importancia de comunicación clara y del reconocimiento de la pérdida, asi como la formación de profesionales para trabajar con situaciones de muerte y luto.

Palabras clave: muerte, luto, relaciones padres-niños, profesional de la salud

O impacto do diagnóstico e o processo de adoecimento de uma criança colocam os cuidadores frente a um mundo desconhecido, em que há diferentes desdobramentos na vida dos pais. Entre esses, se destacam as demandas do tratamento, as exigências de cuidado, o rearranjo da rotina da familia, que se entrelaçam às imprevisibilidades provenientes da doença e a ameaça da iminência da perda do filho. Isso, por sua vez, gera sentimentos de incertezas, fragilidade, desgaste emocional, falta de controle e vulnerabilidade (Jordan et al., 2015).

Diante disso, os pais podem assumir grande volume de tarefas e de responsabilidades associadas à assistência, de modo a impactar sua própria saúde (Collins et al., 2016) e provocar sofrimento ao acompanhar momentos críticos de piora, além da presença em procedimentos dolorosos para a criança (Ljungman et al., 2016). Nesse processo, pesquisas sinalizam a importância da participação dos pais no cuidado, de modo a auxiliar na elaboração do luto e na diminuição do sentimento de culpa (Meert et al., 2009; Pazes et al., 2014; Pereira, 2014). Por elaboração se entende o trabalho psíquico de gerir e integrar as excitações que chegam ao psiquismo, visando a estabelecer relações associativas entre elas, podendo, com isso, transformá-las em um registro simbólico (Laplanche \& Pontalis, 2001).

Segundo Freud (1917/2006), o luto consiste em uma reação natural à perda, cujo trabalho se inicia frente ao teste de realidade, que indica que o objeto amado não existe mais, razão pela qual é preciso que a libido investida nele seja redimensionada. Face a isso, há uma retirada gradual dessa energia libidinal vinculada às lembranças e às expectativas, as quais a relacionam ao objeto perdido. Parkes (1998) acrescenta o caráter processual e singular do luto, no qual os quadros clínicos possuem características variadas e dinâmicas, uma vez que se mesclam e se substituem. Nesse percurso, os sujeitos enlutados encontram-se com a necessidade de reconfigurar funções e papéis, transformar a rotina, bem como lidar com aqueles aspectos que não estão mais presentes. Isso, por sua vez, implica em encontrar e atribuir significados à experiência da perda. Os significados constituem representações que possuem uma função estruturante, em torno das quais os sujeitos organizam as suas vivências, incluindo sua própria relação com os processos de saúde e doença (Turato, 2013).

Além da participação no cuidado, o contato com a criança após a morte - possibilitando rituais de despedida - é apresentado como um elemento facilitador do processo de luto. De acordo com Muza et al. (2013), os pais que tiveram oportunidade de contato e de despedida da criança se mostraram gratos e com um sentimento de ter sua perda reconhecida, enquanto aqueles que não tiveram a mesma oportunidade evidenciaram uma lacuna referente à tal vivência, o que pode indicar dificuldades na elaboração da perda. Nesse tocante, destaca-se a importância do papel dos profissionais de saúde na comunicação da notícia da morte, no acompanhamento no momento de tocar o filho morto, no planejamento de rituais fúnebres e sepultamento e na organização dos pertences da criança (Faria-Schützer et al., 2014).

Diante disso, evidencia-se a relação com a equipe de saúde durante o período de hospitalização da criança, como um elemento que repercute no trabalho do luto, fator que foi evidenciado em outros estudos (Dutta et al., 2020; Jordan et al., 2015; Ljungman et al., 2016; Pohlkamp et al., 2019; Santos et al., 2019). Nesse contexto, os principais aspectos da pesquisa de Snaman et al. (2016) ponderam acerca dos seguintes pontos: (i) a importância das relações entre pais enlutados e a equipe de saúde e da continuidade de tais relações; (ii) a boa comunicação entre os pais e a equipe; (iii) o impacto de experiências negativas entre os profissionais da saúde e familiares no luto parental; e (iv) a relevância da instituição de saúde no luto dos pais. Relativo ao primeiro aspecto, ressalta-se a importância da continuidade do cuidado e do suporte ao luto, assim como da 
assistência psicológica durante a hospitalização e após a morte (Donovan et al., 2015; Meert et al., 2009; Pereira et al., 2018; Snaman et al., 2016).

Na pesquisa de Ljungman et al. (2016), cujo objetivo foi descrever as experiências de pais enlutados, $81 \%$ dos pais e $75 \%$ das mães relataram experiências negativas durante o tratamento do filho. Essas se referiram, entre outras, à percepção dos profissionais como hostis, estressados e insensiveis, além de terem sido tecidas críticas a respeito da comunicação da iminência da morte da criança e questionamentos sobre erros no diagnóstico e nas intervenções. Ao encontro disso, o estudo de Santos et al. (2019), que visou compreender os significados atribuídos por pais enlutados aos relacionamentos com profissionais da saúde durante a hospitalização do filho em final de vida, apontou que os entrevistados manifestaram emoções negativas em relação à equipe de saúde, haja vista as dúvidas e as questões pendentes sobre as condutas no tratamento e cuidado do filho.

Nessa direção, estabelece-se uma correspondência entre a confiança nas atividades prestadas pelos profissionais e menores indícios de complicações na elaboração do luto, como aponta o estudo de Pohlkamp et al. (2019). Este evidenciou que, além da sensação de o filho ter sofrido com o tratamento, a percepção de não ter recebido informações suficientes das repercussões da doença e de como desempenhar o cuidado, indicou maiores dificuldades de processamento do luto para mães. Já para os pais, estas dificuldades se relacionaram, além de outros fatores, à percepção de informações insuficientes sobre a trajetória de doença da criança (Pohlkamp et al., 2019). Por outro lado, as experiências positivas com os profissionais, tais como a disponibilidade de suporte social, a confiança de que todas as necessidades do filho haviam sido supridas, a assimilação de terem recebido cuidado integral, o apoio e a sensibilidade no momento da perda, auxiliaram na construção de significados e na transição para nova realidade como pais enlutados (Dutta et al., 2020; Ljungman et al., 2016; Pohlkamp et al., 2019; Santos et al., 2019)

Aponta-se que a relação com a equipe pode sofrer ruidos diante do mal-estar que, por vezes, instala-se entre os familiares e os profissionais (Quintana, et al., 2011), e diante da responsabilização da equipe quando a dor se torna insuportável para os pais (Rios et al. 2016). Acrescenta-se que, por parte dos profissionais da saúde, há uma formação que carece de discussões sobre aspectos relacionais, uma vez que, no ensino, predominam os aspectos voltados à técnica e à cura (Azeredo, 2016; Lima \& Andrade, 2017). Ainda, há o fato de que, conforme mostra a pesquisa de Cherer et al. (2013), a morte de uma criança pode causar maior afetação dos profissionais, tendo em vista as concepções que envolvem a infância e a expectativa de sucesso terapêutico.

Diante do exposto, entende-se que a singularidade dos sentimentos de pais frente ao adoecimento e morte de um filho, bem como a relação com a equipe durante e após a hospitalização é fundamental tanto para a vivência dos pais no processo de adoecimento, quanto para a elaboração da perda. Nesse sentido, a relevância do presente estudo consiste em possibilitar o desenvolvimento de perspectivas teóricas que subsidiem as práticas dos profissionais em saúde diante de pais que vivenciam o processo de adoecimento e morte do filho, haja vista a possibilidade de visibilizar as experiências dos pais enlutados em relação a esse contexto e ao cuidado da criança, assim como os desdobramentos provocados por tais experiências nos processos de luto. Portanto, é possivel favorecer que a equipe de saúde oportunize experiências que facilitem o cuidado e o processamento da perda. Para tanto, o objetivo deste artigo foi compreender os significados atribuidos por pais enlutados às suas experiências diante da perda do filho e aos cuidados desempenhados pela equipe de saúde.

\section{Método}

O método qualitativo foi escolhido por melhor abordar o assunto, uma vez que busca explorar e aprofundar questões existenciais, relacionais, crenças e opiniões dos sujeitos. Com base nisso, é possivel explorar as interpretações que os indivíduos fazem sobre como vivem, sobre si mesmos, sobre o que sentem e pensam (Minayo, 2014; Turato, 2013). 
Nesse contexto, desenvolveram-se 11 entrevistas, em que participaram 11 mães e cinco pais cujos filhos morreram na infância por motivo de doença. A idade dos entrevistados teve uma média de 38 anos. $O$ acesso a estes participantes aconteceu por meio das informações viabilizadas, com prévia autorização do órgão competente, pela Vigilância Epidemiológica da cidade, com base nas declarações de óbitos disponiveis no Sistema de Informação de Mortalidade. A lista continha os seguintes dados: nome e data de nascimento da criança, causa do óbito, nome dos pais e endereço; informações que possibilitaram a identificação dos participantes por meio de um dos critérios previamente estipulados, qual seja: a criança ter idade de até 12 anos. Cabe mencionar que a lista foi concedida já em consonância a outros critérios de inclusão, como: o tempo de óbito ter acontecido entre um mês e um ano (em relação ao mês de acesso), os sujeitos residirem na cidade onde a pesquisa estava sendo desenvolvida e a causa da morte ter sido por doença. Tendo em vista o periodo de busca dos participantes em seus locais de moradia, o tempo em relação à perda variou de quatro a dezesseis meses.

A idade das crianças foi estabelecida conforme a Lei 8.069/1990, que discorre sobre o Estatuto da Criança e do Adolescente (ECA) e considera criança a pessoa de até 12 anos de idade incompletos. A idade dos filhos falecidos variou entre zero dia - considerando crianças que, por conta de alguma doença, nasceram mortas - a 12 anos. Tal amplitude de idade se deu, em especial, pela dificuldade de encontrar todos os pais, visto que muitos endereços registrados estavam incompletos ou incorretos, ou, ainda, pelo fato de os sujeitos não habitarem mais a mesma moradia.

A coleta de dados, realizada no periodo de maio a outubro de 2016, efetivou-se por meio de entrevistas semiestruturadas com questões abertas, que contaram com um roteiro constituido por tópicos (Minayo, 2014). Tais tópicos contemplavam a abrangência das informações alinhadas aos objetivos, como o recebimento da notícia do adoecimento, o processo de tratamento e/ou hospitalização, os sentimentos frente à perda iminente, a rede de suporte com a qual os pais contavam, os sentimentos que emergiram frente à morte do(a) filho(a) e a experiência diante da ausência do(a) filho(a). As entrevistas tiveram duração média de uma hora e meia a duas horas, foram gravadas em áudio, com prévio consentimento dos entrevistados e, posteriormente, transcritas.

Diante disso, foram realizadas 11 entrevistas, momento em que houve saturação teórica dos dados, ou seja, que as informações começaram a se repetir e considerou-se que novas coletas não acrescentariam informações significativas para a discussão dos objetivos propostos no estudo (Turato, 2013). Da totalidade das entrevistas (11), cinco foram realizadas com ambos os pais. Nas demais (seis), houve participação apenas das mães, por motivos como: o pai não querer participar, delegar esse assunto para mãe, estar em outra cidade, o pai ter falecido ou a mãe alegar não ter mais o contato do pai. Referente a este último caso, não havia registro do contato do pai na lista que foi concedida à pesquisadora. Atendendo aos principios éticos, a identidade dos pais foi preservada, bem como a dos filhos, de modo que os nomes foram trocados por $\mathrm{M}$, quando mãe, ou $\mathrm{P}$, quando pai, seguidos por um referente numérico. A Tabela 1 visa identificar os participantes da pesquisa, situando-os em relação às características da perda do filho, tais como: a idade da criança no momento da morte, a causa do falecimento e o tempo relativo à perda, considerando o momento da entrevista. Cabe mencionar que, em relação à causa da morte, foi acrescentado o motivo que constava oficialmente nos dados do Sistema e, ao lado, a explicação atribuida pelos pais, quando esses a fizeram. 
Tabela 1 - Caracterização dos participantes

\begin{tabular}{|c|c|c|c|}
\hline Mãe/Pai & $\begin{array}{l}\text { Idade/sexo } \\
\text { do (a) filho(a) }\end{array}$ & Causa da morte & Tempo da perda \\
\hline M1 & 7 dias/M & $\begin{array}{l}\text { Infecção própria do período perinatal não especificada/ } \\
\text { Superbactéria }\end{array}$ & 4 meses e 27 dias \\
\hline M2 & $11 \mathrm{dias} / \mathrm{F}$ & Complicações cardiacas & 1 ano e 14 dias \\
\hline M3 & 5 dias/M & Infecção própria do período perinatal não especificada & 1 ano e 2 meses \\
\hline M4 & 2 anos/M & Malformação não especificada do coração & 6 meses \\
\hline M5 & $\mathrm{O} / \mathrm{M}$ & $\begin{array}{l}\text { Feto e recém-nascido afetados por doenças infecciosas } \\
\text { e parasitárias da mãe/Erro médico }\end{array}$ & 6 meses e 20 dias \\
\hline M/P 6 & 9 anos/M & Neoplasia maligna do encéfalo, não especificado & 1 ano e 3 meses \\
\hline M7 & 8 anos/F & Cardiomiopatia dilatada & 9 meses \\
\hline$M / P 8$ & 12 anos/F & Morte sem assistência/Rompimento de uma veia & 1 ano e 4 meses \\
\hline M 9 & $\mathrm{O} / \mathrm{F}$ & Recém-nascido com peso muito baixo & 6 meses \\
\hline$M / P 10$ & 4 dias/F & Síndrome da angústia respiratória do recém-nascido & 7 meses \\
\hline M/P 11 & $1 \mathrm{ano} / \mathrm{M}$ & Hidrocefalia congênita não especificada & 7 meses \\
\hline
\end{tabular}

Destaca-se que, em sete casos, o primeiro contato foi presencial, pelo fato de não constarem as informações telefônicas, o que levou à busca pelos participantes por meio de seus endereços residenciais. Nos outros casos, os sujeitos haviam mudado o local de moradia e foi possivel obter seus números de telefone por intermédio de vizinhos. Ao encontrar os pais indicados na lista, o motivo do contato foi explicado, bem como os detalhes da pesquisa. Na sequência, foi perguntado sobre o desejo de participar da entrevista, suas possibilidades e local que julgavam ser adequado, podendo escolher entre a própria casa ou uma sala na universidade a qual a pesquisa estava vinculada. A M7 solicitou que a entrevista fosse realizada no hospital, onde ela levaria o filho para uma consulta médica e a entrevista 11 foi em uma sala da universidade, sendo que as demais foram realizadas nas residências dos participantes.

A pesquisa teve aprovação do Comitê de Ética em Pesquisa da Universidade Federa de Santa Maria (UFSM), à qual o estudo estava vinculado, sob o número 52750016.6.0000.5346 e esteve em consonância à Resolução 466/2012 do Conselho Nacional de Saúde. Todos os participantes receberam o Termo de Consentimento Livre e
Esclarecido, o qual foi explicado, em linguagem acessivel, antes das entrevistas, que se iniciaram após a concordância dos participantes. Ressalta-se que, em conformidade aos preceitos éticos, a pesquisa previa o encaminhamento ao atendimento psicológico dos participantes que demostrassem aspectos que apontassem para um processo de luto comprometido ou que, por meio da entrevista, ficassem significativamente mobilizados. Além disso, considerando a formação da pesquisadora principal na área da psicologia, previa-se o cuidado de que, frente à excessiva sensibilização dos pais no momento da entrevista, pudesse haver um espaço de acolhimento imediato aos participantes.

A análise dos dados foi realizada por meio da análise de conteúdo temática, segundo Bardin (2010), conforme prezam as etapas: (a) pré-análise; (b) exploração do material; e (c) tratamento dos resultados obtidos e interpretação. Nesse sentido, as entrevistas foram lidas e relidas pela pesquisadora e outros três colaboradores, buscando-se estabelecer os núcleos de sentido (Minayo, 2014) que guiaram a organização das categorias temáticas. Segundo Turato (2013), é possivel considerar o critério de repetição, que preconiza os pontos 
reincidentes a serem destacados, e o critério de relevância, em que determinada(s) fala(s), sob a ótica dos pesquisadores, é rica em conteúdo, sendo capaz de responder ao objetivo proposto.

\section{Resultados e discussão}

As categorias temáticas foram delineadas conforme os significados atribuidos pelos pais às suas experiências relativas ao filho e seus desdobramentos. Além disso, foram organizadas em relação à percepção dos pais sobre os cuidados desempenhados pela equipe de saúde durante a hospitalização do filho no processo de adoecimento. Os elementos que emergiram da análise guiaram as discussões propostas sobre as categorias.

\section{Experiências dos pais relativas ao filho}

Nesta categoria, foram abordados os significados atribuídos às experiências dos pais em relação ao contato com os filhos durante a hospitalização e/ou morte e aos cuidados desempenhados. Frente a isso, essa discussão foi balizada pelos elementos relativos ao contato físico com o filho vivo e diante de sua morte, além da participação dos pais no cuidado da criança.

Observou-se no relato de alguns pais que a possibilidade de contato físico durante a hospitalização foi limitada por conta dos aparelhos que estavam conectados à criança. A dificuldade de estabelecer tal contato desencadeou, em muitas mães, sofrimento, como exemplificou a M2: "eu não pude pegar ela no colo, porque ela tava sempre com os aparelhos. (...) E eu fico triste com isso, que eu não pude pegar ela no colo" (M2, comunicação pessoal, 9 maio 2016). Visualiza-se que essa limitação impede que as mães desenvolvam, de forma plena, sua função materna, em que o contato físico é um componente primordial. O contato, mesmo que breve, pareceu adquirir uma importância ímpar no processo de elaboração após a morte, uma vez que M3 comparou a diferença entre a perda de dois filhos:

Fez! Tu vai dizer: como? Não, porque aquele eu não enxerguei o rosto. Eu não toquei nele, eu não peguei ele. Tu entendeu? Eu não sei te explicar. É bem diferente. (...) Quando tu pega, tu olha, tu vê inteiro, tu vê respirando, tu vê no teu colo, nas tuas mãos. Botaram em cima de mim esse nenê, eu abracei, cheio de sangue, eu abracei e beijei com tanto amor. (M3, comunicação pessoal, 27 maio 2016)

É possivel refletir que, para essa mãe, diante do contato, o bebê tornou-se real, uma vez que houve uma experiência com ele, em que ela pôde reconhecê-lo como filho. Na mesma direção, o toque físico, que intermedeia o contato com a realidade da perda, mostrou-se importante após a morte. Isso encontra correspondência no que Freud (1917/2006) aponta sobre o teste de realidade, que indica que o objeto amado não mais existe, auxiliando em aspectos que vão desde a compreensão da existência do filho, até a concretização da perda. A M10 falou que, em um primeiro momento, recusou o convite de pegar a filha, mas o contato foi estimulado pela profissional:

Dai ela disse 'tá, mas encosta nela', ai eu
só encostei, (...) ai quis pegar. (...) Na hora
de pegar ela deu aquele bah... Quando
o P10 colocou ela no meu colo... Ai deu
aquele baque. (...) E aí a gente enterrou
ela, a gente levou ela, eu levei ela no
meu colo até Inome cidade] e a gen-
te enterrou ela lá. (M10, comunicação
pessoal, 19 out. 2016)

O contato com o corpo, mediante a possibilidade de se despedir, foi apontado por estudos como um elemento que possivelmente contribui para uma melhor elaboração do luto. Reflete-se que esse contato dá encaminhamento para os rituais de despedida, os quais também são considerados importantes para tal elaboração, uma vez que permitem o reconhecimento social da perda (Faria-Schützer et al., 2014; Muza et al., 2013).

A participação no cuidado, por sua vez, é destacada como um relevante elemento no processo (Meert et al., 2009), além de um fator decisivo para o modo como os cuidadores vivenciam o luto. A possibilidade de desempenhar o cuidado até a morte da criança propicia um sentimento de tranquilidade devido à sensação de "missão cumprida", o que indica um melhor encaminhamento da elaboração da perda (Pazes et al., 2014) e, também, a diminuição de um possivel sentimento de culpa após a morte (Pereira, 2014). 
Esses aspectos permitem refletir que tais elementos podem ser percebidos como componentes que funcionam estabelecendo, por intermédio do trabalho psíquico, relações entre eles, inerente à proposta de elaboração psíquica e consequente simbolização da perda (Laplanche \& Pontalis, 2001), conferindo significados à experiência do luto. Nesta pesquisa, os pais dialogaram sobre a realização desses cuidados:

\section{P11: (...) Mais seguro.}

M11: Eu acho que se não tivesse feito isso (...) hoje a gente não ia estar com a cabeça que a gente tá, bem como a gente tá.

P11: Com tranquilidade, digamos assim.

M11: Nos tornou pai. Não ficou aquela coisa assim ó: 'ah, eu não fui pai do meu filho porque ele tava no hospital'. Não, a gente foi. (P11 e M11, comunicação pessoal, 22 out. 2016)

Nesse contexto, observa-se que o desempenho dos cuidados dos filhos levou os pais a sentirem suas funções parentais garantidas. A possibilidade de conhecer as necessidades específicas das crianças e as responsabilidades que envolvem o cuidado faz com que os pais se sintam como protetores dos filhos (Collins et al., 2016). Tal sentimento de proteção parental, em especial a materna, pode encontrar sustentação na fantasia de cura atribuida às ações das mães diante da intensa relação de cuidado desenvolvida no adoecimento (Quintana et al., 2011).

Ademais, assumir o papel de cuidador pode ser considerada uma maneira de minimizar os impactos do tratamento da criança, além de que o conhecimento adquirido pelos pais ao longo desse processo é considerado útil para o manejo de situações urgentes. Nesse sentido, desenvolve-se a concepção de que outros familiares, amigos e profissionais da saúde não compreendem inteiramente as necessidades dos filhos. Isso possibilita o desencadeamento de sentimentos de ansiedade e culpa, o que, por sua vez, pode levar os pais a assumirem os cuidados integralmente (Collins et al., 2016). Consoante a isso, a fala da M4 explicitou:
Ela só virava e gritava: 'mãe, o mano tá vomitando!', aí eu só largava tudo e saía correndo pra acudir ele, porque, a maioria das vezes, ele regurgitava e saiu... pela narina. E tinha que... aspirar. (...) Porque tem muitas mães que... Deus o livre, se tiver que aspirar a criança, sai do quarto e deixa pras enfermeiras, as técnicas. E eu via elas fazendo e eu tinha muita vontade de eu fazer, porque eu achava que eu fazendo ia ser menos dolorido pra ele (...). (M4, comunicação pessoal, 22 jun. 2016)

Na fala da M4, a realização dos procedimentos também apareceu no sentido de causar menos dor ao filho, o que encontra correspondência com o estudo de Collins et al. (2016). Ademais, em seu discurso, o cuidado em torno do filho era principalmente desempenhado por ela, reforçando que essa função ainda é, predominantemente, materna (Quintana et al., 2011). Por outro lado, a mãe sinalizou que "(...) não foi fácil de ver tudo que ele sofreu. [chora]" (M4, comunicação pessoal, 22 jun. 2016), o que remete à possibilidade de a participação no cuidado desencadear sentimentos de angústia frente aos procedimentos, na medida em que os pais acompanham as dores provocadas pelo tratamento e, muitas vezes, precisam submeter os filhos a tais intervenções, gerando sofrimento na criança e no cuidador (Ljungman et al., 2016).

Denota-se, desta categoria, que o modo como os pais vivenciaram a participação no cuidado e no contato físico com o filho - vivo ou não - remete a questões subjetivas, tendo em vista que os cuidadores referiram a importância do contato físico e do desempenho do cuidado como fatores positivos, os quais, embasados pela literatura, apontam para um melhor encaminhamento do luto. No entanto, o desempenho de tais funções pode levar a sentimentos de angústia e de sofrimento, pelo fato de os pais se sentirem sobrecarregados ou por estarem vivenciando uma situação demasiadamente dolorosa. Os elementos externos, tal como o cuidado da equipe de saúde no manejo dessas situações, são fatores fundamentais para que essas experiências sejam integradas, de modo que haja acolhimento e respeito diante da participação dos pais. 


\section{Significados atribuidos aos cuidados} desempenhados pela equipe de saúde

Esta categoria caracteriza-se tanto pelas percepções positivas dos pais em relação à equipe de saúde, em que os profissionais são retratados como compreensivos e atenciosos, quanto negativas, as quais evidenciam conflitos nessa vinculação. Assim, os aspectos discutidos se referem às seguintes questões: a atenção e a comunicação compreensiva, as dificuldades no diálogo entre os cuidadores e os profissionais, a desconfiança e a culpabilização da equipe pela morte da criança, a percepção de que os profissionais seriam insensiveis e despreparados, e a falta de acompanhamento psicológico e seguimento da assistência.

No que tange às concepções da equipe como atenciosa, a fala da M1 exemplifica percepções que permearam a narrativa de outros participantes quando relataram terem se sentido bem-assistidos, com base em uma relação de atenção: "(...) eu agradeci o médico porque (...) muito compreensivos. Assim... atenciosos com ele. A enfermeira mesmo, a enfermeira que trouxe 0 copo d'agua chorou comigo". (M1, comunicação pessoal, 28 abr. 2016) Esse recorte encontra correspondência com o estudo de Meert et al. (2009), em que os pais valorizaram a atitude compassiva dos profissionais. Tal comportamento foi destacado como um importante elemento desenvolvido pela equipe, por meio de ações como: promover ambientes adequados durante processo de morte, oferecer um copo de água, acompanhar os pais após a morte da criança, estarem isentos de julgamento e compartilharem os momentos de dor e sofrimento, entre outros. Esse processo pode ser identificado na fala da M10, na qual se visualiza uma comunicação que a mãe percebeu como cuidadosa: "quando a gente desceu era a médica... era um anjo, nossa, um encanto de pessoa, era aquelas pessoas que falam assim, com a voz desse jeito [voz suave] (...). Ela foi... nossa, ela foi acalmando de uma maneira que..." (M1O, comunicação pessoal, 19 out. 2016).

Nesse contexto, os pais do estudo de Snaman et al. (2016) valorizaram mais as ações dos profissionais focadas na presença e na compreensão do que aquelas estritamente técnicas, voltadas para cura e intervenções. Dentre elas, destaca-se a comunicação adequada acerca do adoecimento e seus desdobramentos, isto é, a transmissão da informação de modo que as expectativas geradas sejam ajustadas. Nesse sentido, a comunicação com a equipe se torna parte integrante dessa vivência, uma vez que ao situar os cuidados, permite que os pais se sintam envolvidos o que, por sua vez, confere sentido ao papel parental (Jordan et al., 2015). Ao encontro disso, destaca-se que a valorização do acompanhamento, o amparo emocional disponibilizados pelos profissionais e o apoio psicossocial representam aspectos que podem contribuir na transição do papel de pais cuidadores para pais enlutados (Dutta et al., 2020). Desse modo, reitera-se que a importância dada à dor dos pais demonstra o reconhecimento da sua perda, fator destacado como essencial para o processo de luto (Muza et al., 2013).

Por outro lado, observaram-se dificuldades inerentes ao diálogo entre a equipe e os familiares. Para o $\mathrm{P}_{3}$, os profissionais não comunicaram claramente a morte do filho, o que gerou uma cena que o impressionou: "(...) O pior de tudo isso foi ver ela conversando com o nenê achando que o nenê tava vivo. Porque elas não disseram nada, só mostraram lá". (P3, comunicação pessoal, 27 maio 2016). Para a M4, as comunicações eram rápidas e a linguagem, porvezes, incompreensivel: "Eles te vêm, assim, é no ligeirão. Te jogam aquele monte de palavras, que as vezes tu não entende nada" (M4, comunicação pessoal, 22 jun. 2016). Segundo a M7, os médicos não se aproximaram para conversar com ela: "(...) nunca chegaram e falaram o que ela tinha, conversar sobre o problema dela comigo... médico não. (...) Eu me sentia meio perdida, como eu ia perguntar alguma coisa também..." (M7, comunicação pessoal, 27 jul. 2016).

Com base nos depoimentos, verificou-se que os pais sentiram que as informações fornecidas pelos profissionais foram insuficientes e incompreensiveis, o que os levou a ter dificuldades no entendimento do que estava sendo comunicado e sentir que estavam "perdidos". Diante disso, reflete-se que tais lacunas podem repercutir 
em dificuldades de entendimento do estado de saúde do filho e distanciar os pais da realidade da perda. Corroborando com o exposto, outras pesquisas relatam queixas dos participantes sobre a comunicação, falta de diálogo entre as especialidades e ausência de um trabalho em equipe, provocando angústia devido a informações incongruentes e conflituosas entre diferentes profissionais (Meert et al., 2009; Snaman et al., 2016). Reitera-se que a percepção de informações insuficientes sobre o percurso e os desdobramentos da doença podem estar na base do desenvolvimento de complicações na elaboração do luto (Pohlkamp et al., 2019).

No que se refere ao impacto da notícia do óbito, visualiza-se que os pais realizam um movimento de busca por explicações para a causa da morte, o que pode vir no sentido de encontrar um responsável por essa; em alguns casos, esse gesto se direciona para culpabilização dos profissionais da equipe de saúde. Isso pode ser pensado com base no que foi apontado por Rios et al. (2016) ao mencionarem que, muitas vezes, quando o sentimento de dor e incerteza se tornam insuportáveis, a angústia dos pais diante da vivência do quadro clínico do filho e a ausência de um controle sobre tal situação ocasionam a atribuição da responsabilização à equipe. Isso pode ser reconhecido na fala da M5, em que atribuiu explicitamente a culpa aos profissionais: "Como é que foi que aconteceu... que eu não tenho recurso nenhum. Mas aquela criança quem matou foi o doutor que fez o parto, tá?!" (M5, comunicação pessoal, 7 jul. 2016). A M5 acreditava que, por sua condição socioeconômica, existia um preconceito da equipe em relação a ela, a qual teria influenciado na suposta negligência. Face a isso, reflete-se que, se, por um lado, houve a percepção da equipe agindo de maneira diferenciada, M5 pareceu reagir, atacando-os com raiva e, em especial, com acusação.

Além disso, tal atribuição de culpa à equipe pode ser pensada considerando-se a distância que se coloca, em alguns casos, entre a família e a equipe dentro da instituição hospitalar. Muitas vezes, instala-se um mal-estar entre o paciente e/ou familiar e os profissionais, o que dificulta a convivência e a interação. Isso faz com que o conjunto de fatores que envolvem a hospitalização gere certo sentimento de impotência nos familiares (Quintana et al., 2011). Nesse sentido, encontrar um culpado pode imbuir os pais de uma sensação de controle, pois frente a um acontecimento incontrolável - e por isso insuportável -, buscar um responsável pelo evento faz com que os sujeitos possam recuperar certo senso de domínio sobre a situação (Parkes, 1998). Assim, situam-se fatores que contribuem para o movimento dos pais na atribuição da culpa à equipe: além da relação, que, por vezes, pode ser conturbada, os pais podem passar a atribuir aquilo que é insuportável a quem esteve mais próximo da criança, nesses casos, à equipe.

Ademais, é possivel que as experiências com a equipe durante a hospitalização sejam significadas como negativas, haja vista a previsão de diagnóstico excessivamente otimista, opções de tratamento não realista, transições entre equipes - resultando na fragmentação do cuidado - e sentimentos de abandono (Snaman et al., 2016). Somado a isso, a relação insatisfatória com a equipe pode provocar a sensação de arrependimento e dúvidas sobre as decisões tomadas no fim de vida (Santos et al., 2019; Snaman et al., 2016), além de repercutir no bem-estar dos pais e indicar para entraves no processamento da perda (Dutta et al., 2020; Pohlkamp et al., 2019).

No presente estudo, os pais relataram sentimento de desconfiança em relação à equipe de saúde, como é possivel visualizar na fala de M10, que acreditava ter havido negligência por parte dos profissionais: "No momento que eu vi aquilo ali eu pensei: se ela colocar isso daí na Rosa, ela não vai resistir de jeito nenhum. (...) A gente sabe que foi negligência. A gente tem certeza absoluta" (M10, comunicação pessoal, 19 out. 2016). Outra participante que sinalizou tais significados foi M3: "não sei se tentaram dar mais remédio pra ele reagir mais rápido, puxar o coisinha pra ele tentar respirar sozinho (...) de repente fizeram isso, não conseguiu vencer respirar sozinho (...) Mas... talvez a gente ache desculpa pra isso..." (M3, comunicação pessoal, 27 maio 2016). 
Tendo em vista as narrativas, entende-se que é possivel que as desconfianças também estejam fundamentadas em uma comunicação que não foi efetiva no que diz respeito ao quadro de saúde do filho, aos procedimentos a serem realizados e suas implicações. Ademais, ao final da fala, a participante diz que "talvez a gente ache desculpa pra isso" remetendo à busca por explicações. 0 hospital e o erro da equipe trazem essa explicação: a "desculpa" para morte de seu filho. Frente a isso, destaca-se que, diante do sofrimento vivenciado, é comum surgirem intensas manifestações emocionais nos pais e que tais sentimentos podem ser direcionados a diferentes representações. No estudo de Pereira (2014), por exemplo, os cuidadores se referiram às experiências dolorosas como associadas ao sofrimento do ente, ao sentimento de revolta contra os serviços de saúde e ao fato de não ter percebido claramente a iminência da morte, o que impossibilitou a vivência desse processo de fim de vida junto ao familiar.

No contexto das considerações acima, reflete-se que tanto a revolta como a acusação podem ser direcionadas à instituição hospitalar como um todo ou a aspectos relacionados a ela, como se verifica nas falas da M5 e M1, respectivamente: "Esse foi o primeiro [parto] na [nome hospital]. Eu sempre tive medo! Porque eu já ouvi falar coisas assim, mas eu nunca pensei que eu ia passar por essa situação... Por o erro de um doutor" (M5. comunicação pessoal, 7 jul. 2016). "(...) me deu uma raiva por causa daquela bactéria do hospital. (...) Uma hora tu tá com um pensamento bom, outra hora tu já... Pensa assim: que imundícia" (M1, comunicação pessoal, 28 abr. 2016). Cabe ressaltar que o ambiente hospitalar costuma ter a representação de um espaço que, por conta das regras institucionais, os familiares cuidadores se percebem "despersonalizados", além carregar concepções como aprisionamento e impotência (Quintana et al., 2011). Isso sugere uma reflexão do hospital como um ambiente cujas caracteristicas conduzem a uma vivência dual: de um lado, a expectativa de cuidado e cura; de outro, uma compreensão negativa em relação às limitações frente ao manejo do desconhecido.
Nesse sentido, o hospital figura como um cenário do qual os entrevistados parecem ter temor, pois se acredita que há uma associação entre o hospital, a perda e as experiências negativas em relação à equipe: "até me ligaram pra ir lá, eu disse: 'não, eu não vou'. Botar os pés lá dentro lá é o mesmo que reviver tudo e pior ainda." (M5. comunicação pessoal, 7 jul. 2016). Em contraste, os pais M11 e P11 relataram percepções positivas: "a gente não ficou com nada ruim do hospital (...) pelo contrário. É que eu acho que a gente passou tanto tempo lá dentro com ele que nos remete a uma coisa boa." (M11, comunicação pessoal, 22 out. 2016). Nessa direção, é possivel pensar que a experiência do tratamento remete a longos períodos de hospitalização, o que pode levar os pais ao cultivo de vínculos com a instituição e, ainda, relacionar tal vivência às lembranças da criança viva. Tal interpretação encontra correspondência com os pais da pesquisa de Snaman (2016), que reforçaram uma forte ligação com o local de atendimento ou de morte do seu filho.

Além disso, com base nos relatos, é possivel verificar a concepção dos profissionais como insensiveis e despreparados, como também fica evidente no depoimento da M10: "aquela CTI, gente do céu, o que tem que ser resolvido é o atendimento daquele lugar, aqueles profissionais não são preparados pra tá lá", (M10, comunicação pessoal, 19 out. 2016), bem como no depoimento de M3: "Eles na nossa frente com o nenê tapado num pano desses de TNT. E aí, todos aqui assim [encena]. Eu e o P3 aqui e eles com o nenê: 'pois é, blabla, vai lavar roupa hoje?'". (M3. comunicação pessoal, 27 maio 2016). Diante do relato de $\mathrm{M} 3$ em relação ao que aconteceu logo após a morte do filho, reflete-se o quanto os pais sentiram aquele momento de dor desvalorizado pelos profissionais, que conversavam assuntos cotidianos, como ela exemplificou: "pois é, blabla, vai lavar roupa hoje?", enquanto carregavam seu filho morto. Entende-se que menosprezar e não reconhecer a dor dos pais diante da perda pode ser um elemento que favoreça o incremento das percepções negativas em relação à equipe.

Coadunado aos resultados da presente pes- 
quisa, outros estudos apontaram para a ausência de sensibilidade e conhecimento, por parte dos profissionais, para lidar com a situação. Os serviços de saúde, por sua vez, foram identificados como inadequados em relação ao manejo de situações de sofrimento (Pazes et al., 2014). Somado a isso, situa-se a percepção dos profissionais como insensiveis e hostis (Ljungman et al., 2016), a concepção de despreparo da equipe diante do suporte ao luto das mulheres que perderam filhos (Pereira et al., 2018), além do sentimento de sofrimento relacionado à desconsideração pela personalidade da criança (Meert et al., 2009).

No que tange à preparação da atuação das equipes, reflete-se acerca da formação dos profissionais da saúde, em que a maior parte das pautas curriculares são direcionadas aos aspectos técnicos, em detrimento de uma formação também voltada aos aspectos humanos e relacionais. Os cursos da área da saúde, de maneira geral, não oferecem espaço para que a relação profissional-paciente seja trabalhada e, desde o início, buscam separar o corpo adoecido do doente (Lima \& Andrade, 2017). Ainda, entende-se, que o fim de vida ou a morte de uma criança pode provocar um maior impacto na equipe de saúde, o que, por sua vez, pode ter incrementado a dificuldade dos profissionais em entrar em contato e transmitir as informações sobre a morte de maneira adequada aos familiares (Cherer et al., 2013). Nesse sentido, imersos no contexto institucional e na vivência de situações limitrofes, acredita-se que os profissionais podem desenvolver recursos emocionais, como defesas psíquicas, com vistas à proteção de si a algo que causa ameaça, levando-os a evitar o contato com o sofrimento do outro e, por isso, não o validando.

Nessa direção, na presente pesquisa, entende-se que a vivência dos pais diante da percepção de uma atuação apática foi marcante, pois representa um elemento relevante nos discursos dos pais. Pensa-se que a maneira como eles se sentiram tratados, assim como o tratamento dado aos seus filhos, é algo que pode se constituir como um atravessamento do processamento da morte. Ao encontro disso, Pohlkamp et al. (2019) apontam, entre outros fatores, que a relação com os profissionais da saúde influencia no desenvolvimento de sintomas que podem desencadear complicações na elaboração da perda. Por outro lado, o sentimento de confiança na equipe, de que havia sido feito o melhor pela criança, e a disponibilização de apoio prático pelos profissionais durante a doença foram elementos mencionados como importantes para o encaminhamento do luto. Assim, as percepções dos pais sobre o modo como o cuidado foi desempenhado pelos profissionais da saúde repercutem nos significados que movimentam o processo de luto, tanto no que se refere ao favorecimento, quanto aos entraves na sua elaboração (Santos et al., 2019).

Ademais, sinaliza-se a importância do acompanhamento dos pais pelos profissionais durante a vivência do adoecimento, a fim de dar conta dos sentimentos que emergem na hospitalização e no processo de fim de vida, assim como é importante o seguimento de tal assistência após a morte. Donovan et al. (2015) indicam a relevância do acompanhamento psicológico estruturado durante o processo de hospitalização e após a morte da criança. Em estudo que buscou investigar os impactos desse apoio, os pais que tiveram assistência assinalaram a sensação de cuidado e suporte e a diminuição do senso de isolamento. O depoimento de M4 evidencia essa importância, uma vez que não encontrava a possibilidade de compartilhar com outras pessoas aquilo que estava acontecendo com o filho: "Lá eu tinha um acompanhamento ótimo com psicólogo. (...) Eu ligava pra casa, avisava que o [filho] tava em estado grave e tal: 'ai, para, não fala isso'. Ninguém quer escutar, nem mesmo teus familiares" (M4. comunicação pessoal, 22 jun. 2016).

Além do acompanhamento psicológico, manter o contato com os membros da equipe, mesmo após a morte da criança, pode ser considerado uma extensão do cuidado (Meert et al., 2009), na medida em que esses vínculos podem funcionar como um fator de suporte ao luto (Snaman et al., 2016). No tocante a isso, o P11 se queixou de falta de continuidade na assistência: "A gente cria bastante laço, bastante amizade, mas é uma coisa assim, 
que não tem seguimento. (...) Eu não me lembro, tirando algum dos profissionais que nos ajudaram, que são amigos pessoais... ninguém perguntou". (P11, comunicação pessoal, 22 out. 2016). Cabe reiterar que a implicação da equipe com os familiares não termina com a comunicação da morte. mas suas responsabilidades para com a familia se estendem à abertura de um canal de comunicação para que os pais retornem ao hospital, se julgarem necessário, para conversas ou esclarecimento de dúvidas (Azeredo, 2016; Pereira et al., 2018).

Diante do exposto na categoria, reitera-se que, no que tange aos significados positivos, é possivel observar que eles se relacionam, especialmente, às características relacionais, tais como atenção, compreensão e aspectos acolhedores diante da comunicação da morte da criança. No tocante às percepções conflitivas, reflete-se que elas são atravessadas por um conjunto complexo e dinâmico, que reúne desde componentes subjetivos - como os recursos disponiveis para lidar com o adoecimento e a morte do filho - até fatores que se referem às atitudes da equipe e ao manejo de situações dolorosas, as quais perpassam o acoIhimento, as comunicações com os familiares e a lacuna na continuidade da assistência. Acredita-se que as percepções ambivalentes dos pais podem ser originadas pela interação de fatores diversos, partindo de aspectos concernentes à intensidade da situação - como as características pessoais de cada sujeito envolvido, o modo e o momento em que se deu a vinculação -, chegando aos diferentes papéis que cada profissional assume na equipe, além de outros elementos que interatuam e levam às nuances dos significados atribuidos. Assim, ressalta-se a importância do cuidado disponibilizado pela equipe de saúde diante dos pais enlutados, a fim de auxiliá-los na vivência dos processos de adoecimento, de fim de vida e, consequentemente, de luto, uma vez que os sentidos dados para essa experiência repercutem no processo de elaboração após a morte.

\section{Considerações finais}

Sinaliza-se a relevância do presente estudo por trazer à tona as perspectivas dos pais, uma vez que parte das pesquisas publicadas sobre essa temática é sob a ótica dos profissionais da saúde. Além disso, destaca-se a predominância de materiais que tratam do luto materno, o que reitera a pertinência dessa pesquisa ao convocar ambos os pais, dando lugar para o luto paterno. Junto a isso, mencionam-se as limitações do estudo, que se referem, especialmente, à amplitude de idade das crianças. Ainda assim, cabe mencionar que, tendo em vista o objetivo desta pesquisa e a complexidade do processo de luto - no qual há dinamicidade dos elementos envolvidos -, não é possível considerar a idade como um fator que tenha interferido na análise e na interpretação dos dados. Sugere-se que novos estudos possam tratar sobre aspectos comparativos no que tange ao processo de luto dos pais e sua relação com a idade da criança.

Com base no que foi trabalhado no artigo, é possivel que os profissionais reflitam sobre sua prática e sobre a importância que ocupam diante da experiência da perda e da elaboração do luto parental, podendo ressignificar sua atuação, a fim de favorecer o desenvolvimento do vínculo com os pais. Desse modo, é possivel que se articule um fator protetivo às intercorrências na elaboração, podendo facilitar o luto saudável.

Situam-se as percepções dos pais em relação aos profissionais, os quais são tidos como despreparados para lidar com as pessoas envolvidas nas situações de adoecimento e morte ou mesmo insensiveis, por se mostrarem pouco acolhedores ou incompreensiveis na transmissão das comunicações. Nesse sentido, o intuito de visibilizar os significados negativos atribuidos ao cuidado desempenhado pelos profissionais da saúde visa, sobretudo, sinalizar pontos que são suprimidos diante do cotidiano institucional exaustivo, mas que repercutem, de maneira negativa, para os outros participantes dessas experiências.

Em relação a isso, reflete-se que os obstáculos em se realizar um diálogo claro e aberto, que possam ser compreendidos pelos pais também revelam certa dificuldade dos profissionais em lidar com a situação vigente. Esses entraves na comunicação podem estar na base das questões 
que se referem à desconfiança dos pais sobre as atuações da equipe no tocante à morte dos seus filhos, na qual, muitas vezes, os profissionais figuram como responsáveis e causadores. Visto que os pais estão tomados pela emoção e por sentimentos decorrentes do próprio processo de assimilação da notícia e do luto, a compreensão inteligivel se torna dificultada, o que aponta para a importância da preparação dos profissionais para as comunicações claras e acolhedoras.

Cabe mencionar os procedimentos pós morte, tais como o cuidado e o respeito ao corpo morto, uma vez que ele segue tendo significado para o familiar. Os profissionais podem, dentro das possibilidades e do desejo dos pais, indicar a importância do contato com este corpo recém-falecido, mediando este encontro. Tais profissionais podem, em especial, dar suporte e auxilio nos encaminhamentos após o óbito, de modo que os pais se sintam acolhidos e seguros. Ainda em vida, reflete-se sobre a possibilidade de os profissionais facilitarem, na medida do possivel e dentro das condições do estado de saúde da criança, a participação no cuidado.

Diante disso, destaca-se a importância de sistematizar locais que possam acolher os pais em suas necessidades, adequando as instituições às demandas dos pacientes e familiares e viabilizando uma experiência mais humanizada, que contribua para que tal vivência se torne menos penosa. Do ponto de vista pragmático, aponta-se para os ajustes referentes ao conforto físico e ambiental, tanto no que se refere à estada dos cuidadores para o acompanhamento dos entes, quanto ao processo de morte. Situa-se, assim, a importância de espaços em que os familiares se sintam confortáveis para vivenciarem o processo de fim de vida e os rituais de despedida.

Além disso, os espaços institucionais deveriam se constituir como locais para que os profissionais possam não só adquirir conhecimentos técnicos em relação às comunicações e o manejo das situações que envolvem a morte de uma criança, mas também compartilhar os sentimentos que emergem nessas experiências, de modo a terem seus lutos reconhecidos e suas dores e dificuldades validadas e respeitadas. Dessa maneira, destaca-se a importância das reuniões em equipe e de momentos especificos para tais discussões, os quais podem se constituir como espaços privilegiados de trocas.

Reitera-se, diante do exposto, que as ações dos profissionais se constituem como atravessamentos tanto na vivência da doença e da hospitalização, como no pós-morte e no processo de elaboração do luto. Imbuídos dessa responsabilidade, os serviços de saúde poderiam se organizar em torno disso, a fim de fornecer preparação para os profissionais lidarem com situações de morte e luto, assim como promover programas que efetivem o acompanhamento dos enlutados.

\section{Referências}

Azeredo, N. S. G. de. (2016). O cuidado com o luto para além das portas das unidades de terapia intensiva: uma aposta e uma proposta [Tese de Doutorado, Universidade Federal do Rio Grande do Sull. https://www.lume. ufrgs.br/bitstream/handle/10183/148127/000998698. pdf? sequence $=1$ \&isAllowed $=y$

Bardin, L. (2010). Análise de conteúdo. Edições 70.

Cherer, E. Q., Quintana, A. M., \& Pinheiro, U. M. S. (2013). Sofrimento e Libertação: Significações Sobre a Morte na UTI Pediátrica. Psico, 44(4), 482-489. http://revistaseletronicas. pucrs.br/ojs/index.php/revistapsico/article/view/10982

Collins, A., Hennessy-Anderson, N., Hosking, S., Hynson, J., Remedios, C., \& Thomas, K. (2016). Lived experiences of parents caring for a child with a life-limiting condition in Australia: A qualitative study. Palliative Medicine, 30(10), 950-959. https://doi.org/10.1177/0269216316634245

Donovan, L. A., Wakefield, C. E., Russell, V., \& Cohn, R. J. (2015). Hospital-based bereavement services following the death of a child: A mixed study review. Palliative Medicine, 29(3), 193-210. https://doi. org/10.1177/0269216314556851

Dutta, O., Tan-Ho, G., Choo, P. Y., Low, X. C., Chong, P. H., Ng, C., Ganapathy, S., \& Ho, A. H. Y. (2020). Trauma to Transformation: the lived experience of bereaved parents of children, BMC Palliative Care, 19(46). https:// doi.org/10.1186/s12904-020-00555-8

Faria-Schützer, D. B., Lovorato Neto, G., Duarte, C. A. M., Vieira, C. M., \& Turato, E. R. (2014). Fica um grande vazio: Relatos de mulheres que experienciaram morte fetal durante a gestação. Estudos Interdisciplinares em Psicologia, 5(2), 113-132. https://doi.org/10.5433/ 2236-6407.2014v5n2p113

Freud, S. (2006). Luto e melancolia. In S. Freud, Edição Standard das Obras Completas de S. Freud (vol. XIV). Imago. (Trabalho original publicado em 1917) 
Jordan, J., Price, J., \& Prior, L. (2015). Disorder and disconnection: parent experiences of liminality when caring for their dying child. Sociology of health and illness, 37(6), 839-55. https://doi.org/10.1111/1467-9566.12235

Laplanche, J., \& Pontalis, J. B. (2001). Vocabulário de psicanálise. Martins Fontes.

Lei no 8.069/1990. (1990). Estatuto da criança e do adolescente. Diário da República. № 83, 13.563.

Lima, M. J. V., \& Andrade, N. M. de. (2017). A atuação do profissional de saúde residente em contato com a morte e o morrer. Saúde e Sociedade, 26(4), 958-972. https://doi.org/10.1590/S0104-12902017163041.

Ljungman L., Boger, M., Ander, M., Ljótsson, B., Cernvall, M., Von Essen, L., Hovén, E. (2016). Impressions That Last: Particularly Negative and Positive Experiences Reported by Parents Five Years after the End of a Child's Successful Cancer Treatment or Death. PLOS ONE, 11(6), e0157076. https://doi.org/10.1371/journal.pone.0157076

Meert, K. L., Briller, S. H., Schim, S. M., Thurston, C., \& Kabel, A. (2009) Examining the Needs of Bereaved Parents in the Pediatric Intensive Care Unit: A Qualitative Study. Death Studies, 33(8), 712-740. https://doi. org/10.1080/07481180903070434

Minayo, M. C. S. (2014). O desafio do conhecimento: Pesquisa qualitativa em saúde (14. ed.). Hucitec.

Muza, J. C., Souza, E. N., Arrais, A. R., \& laconelli, V. (2013). Quando a morte visita a maternidade: atenção psicológica durante a perda perinatal. Revista Psicologia: Teoria e Prática, 15(3), 34-48. http://pepsic.bvsalud.org/scielo. php? script=sci_arttext\&pi$d=S 1516-36872013000300003 \& \operatorname{lng}=p t \& t \operatorname{lng}=p t$

Parkes, C. M. (1998). Luto: estudos sobre a perda na vida adulta (Tradução de Maria Helena Franco). Summus.

Pazes, M. C., Nunes, L., \& Barbosa, A. (2014). Fatores que influenciam a vivência da fase terminal e de luto: perspetiva do cuidador principal. Revista de Enfermagem Referência, 4(3), 95-104. http://dx.doi.org/10.12707/RIII12135

Pereira, I. C. O. (2014). Avaliação do processo de luto: na perspectiva do cuidador enlutado [Dissertação de mestrado, Universidade de Lisboal. https://repositorio. ul.pt/bitstream/10451/23495/1/10975.pdf

Pereira, M. U. L., Gonçalves, L. L. M., Loyola, C. M. D., Anunciação, P. S., Dias, R. S., Reis, I. N., Pereira, L. A. S., Lamy, Z. C. (2018). Comunicação da notícia de morte e suporte ao luto de mulheres que perderam filhos recém-nascidos. Revista Paulista de Pediatria, 36(4), 422-427. https://doi.org/10.1590/1984-0462/:2018:36:4:00013.

Pohlkamp, L., Kreicbergs, U., \& Sveen, J. (2019). Factors During a Child's Illness Are Associated With Levels of Prolonged Grief Symptoms in Bereaved Mothers and Fathers. Journal of Clinical Oncology, 38(2), 137-144. https://doi.org/10.1200/JC0.19.01493

Quintana, A. M., Wottrich, S. H., Camargo, V. P., Cherer, E. de Q., \& Ries, P. K. (2011). Lutos e lutas: Reestruturações familiares diante do câncer em uma criança/ adolescente. Psicologia Argumento, 29(65), 143-154. https://doi.org/10.7213/rpa.v2gi65.20035
Resolução n. 466, de 12 de dezembro de 2012. Diretrizes e normas regulamentadas de pesquisas envolvendo seres humanos. Ministério de Saúde/Conselho Nacional de Saúde. http://conselho.saude.gov.br/resolucoes/2012/Res0466.pdf

Rios, T. dos. S., Santos, C. S. S., \& Dell'Aglio, D. D. (2016) Elaboração do processo de luto após uma perda fetal: relato de experiência. Revista de Psicologia da IMED, 8(1), 98-107. https://doi.org/10.18256/2175-5027/psico-imed.v8n1pg8-107

Santos, M. R. dos., Wiegand, D. L., Sá, N. N. de., Misko, M. D., \& Szylit, R. (2019). Da hospitalização ao luto: significados atribuidos por pais aos relacionamentos com profissionais em oncologia pediátrica. Revista da Escola de Enfermagem da USP, 53, e03521. https://doi. org/10.1590/s1980-220X2018049603521

Snaman, J. M., Kaye, E. C., Torres, C., Gibson, D. V., \& Baker, J. N. (2016). Helping Parents Live With the Hole in Their Heart: The Role of Health Care Providers and Institutions in the Bereaved Parents' Grief Journeys. Cancer, 122, 2757-2765. https://doi.org/10.1002/cncr.30087

Turato, E. R. (2013). Tratado da metodologia da pesquisa clínico-qualitativa: Construção teórico-epistemológica discussão comparada e aplicação nas áreas da saúde e humanas (6. ed.). Vozes.

\section{Cristine Gabrielle da Costa dos Reis}

Doutora em Psicologia pela Universidade Federal de Santa Catarina (UFSC), em Florianópolis, SC, Brasil.

\section{Alberto Manuel Quintana}

Doutor em Antropologia Clínica pela Pontifícia Universidade Católica de São Paulo (PUC-SP), em São Paulo, SP, Brasil; professor titular da Universidade Federal de Santa Maria (UFSM), em Santa Maria, RS, Brasil.

\section{Luísa da Rosa Olesiak}

Mestre e doutoranda em Psicologia pela Universidade Federal de Santa Maria (UFSM), em Santa Maria, RS, Brasil.

\section{Fernanda Nardino}

Mestre pela Universidade Federal de Santa Maria (UFSM), em Santa Maria, RS, Brasil.

\section{Mikaela Aline Bade München}

Psicóloga graduada pela Universidade Federal de Santa Maria (UFSM), em Santa Maria, RS, Brasil. 


\section{Endereço para correspondência}

Cristine Gabrielle da Costa dos Reis

Rua Carlos Uhr, 875

97070-220

Santa Maria, RS, Brasil

Os textos deste artigo foram revisados pela Poá Comunicação e submetidos para validação do(s) autor(es) antes da publicação. 